\title{
Shadow-Reading Effect on Reading Comprehension: Actualization of Interactive Reading Comprehension: (A Vygotskyan View!)
}

\author{
Elahe Sadeghi ${ }^{1}$, Akbar Afghari ${ }^{1} \&$ Gholam-Reza Zarei ${ }^{2}$ \\ ${ }^{1}$ Islamic Azad University, Isfahan (Khorasgan) Branch, Isfahan, Iran \\ ${ }^{2}$ Isfahan University of Technology, Isfahan, Iran \\ Correspondence: Elahe Sadeghi, Islamic Azad University, Isfahan (Khorasgan) Branch, Isfahan, Iran. Tel: \\ 66-81-812-4862. E-mail: elahesadeghi20@yahoo.com
}

Received: December 21, 2015 Accepted: February 12, 2016 Online Published: February 14, 2016

doi: 10.5539/elt.v9n3p130 URL: http://dx.doi.org/10.5539/elt.v9n3p130

\begin{abstract}
Reading comprehension has been the main concern for second language learners and researchers. Today with rising interests towards Vygotskyan Sociocultural Theory (SCT), attempts have been made to insert Vygotskyan approach into Foreign/Second Language classrooms emphasizing the role of scaffolding and meaningful interactions to promote learners' comprehension. Having this on mind, the current study used shadow-reading as a means of meaning internalization to see if it affects on reading comprehension. To this end, 52 junior EFL learners from two universities were randomly assigned to experimental and control groups. A pretest of reading comprehension including 4 reading passages with 20 Multiple Choice items was administered to the learners to see if they were at the similar level of reading comprehension. During 10 sessions, the learners were provided with shadow-reading strategy in which they were required to listen and repeat the passage in a well-disciplined imitative task and, then summarize what they had comprehended from the text. A reading comprehension post test was also administered at the end of the semester after 10 sessions of conducting shadowing. The data of the first and the last sessions was analysed. The findings of the study showed that shadow-reading has significantly influenced learners' comprehension. The results also lent support to Vygotskyan theory in that using shadowing as a means of meaningful imitation and interaction facilitates comprehension among learners. The results also shed light on the way through which instructors try to promote learners' comprehension. It seems that shadow reading due to its sociocultural traits can be used as an appropriate means of promoting reading comprehension all over the world.
\end{abstract}

Keywords: comprehension crisis, shadow-reading, vygotskyan sociocultural theory

\section{Introduction}

The issue of comprehension has been of the main concerns of researchers and experts in foreign language (L2) classrooms. Many researchers have concentrated their studies on finding ways to enhance learners' reading comprehension ability. Foreign language learners have tried many strategies like extensive and intensive reading, chunking the texts, top-down and bottom-up reading, generating questions from the text and answering them and etc. to enhance comprehension in reading comprehension classes. Although reading comprehension is emphasized in L2 classes, although learners are encouraged not to look all unknown words up in dictionary; although the learners put much time and energy into improving their reading comprehension ability, they have still difficulty getting and retaining the meaning. Learners find out the meaning of a sentence with much effort while they become trapped in the same structure of the next sentence just some time later.

Text comprehension crisis is not limited to a specific context or situation; it has drawn many scholars' attention all over the world and has been looked at from different perspectives such as cognitive and sociocultural perspectives (Kern, 2000). Within cognitive paradigm, reading and listening are considered as cognitive, intrapersonal problem-solving processes that occur within the listener/reader's mind and are closely related to his/her prior knowledge (Bernhardt, 1991; Buck, 2003; Swaffar, Arens, \& Byrnes, 1991). Reading comprehension has been viewed from two different approaches, one set of research studies view text comprehension as meaning extracting process while others see it as meaning-constructing one (e.g., Buck, 2003; Roebuck, 1998; Kern, 2000). 
Regarding comprehension crisis, sociocultural theory of Vygotsky states that imitation could play an important role in meaningful learning. Vygotsky $(1986,1978,1996)$ has repeatedly stated that comprehension plays a central role in the learning process and comprehension. The extent to which imitation can promote comprehension has been a matter of debate in recent years, and it has been brought into focus in totally different schools of thought from behaviourism to socioculturalism. Furthermore, comprehension and its enhancement have been a great concern for the second language researchers (e.g., Buck, 2003; Roebuck, 1998; Kern, 2000). Although many researchers have emphasized interactive reading strategies to modify and improve reading comprehension, there exists a great silence in what ways and how reading comprehension could improve. Furthermore, the role of social factors and cultural agents has been disregarded as the potential to improve learners' comprehension. This study aimed to investigate what role can shadow reading play in the promotion of reading comprehension among Iranian learners of English as a Foreign Language (EFL). Shadow-reading is a classroom activity in which learners assist each other in reading an L2 text through interactive reading, repeating and summarizing (Guerrero \& Commander, 2013). As Murphey (2001, p. 4) asserts, repetition is the heart of shadow-reading which promotes "language learning and goes beyond the mere echoing of input material. Murphey believes that shadowing is a step between being other-regulated and self-regulated, at first it seems that we are under the control of others' language (other-regulated), but as we repeat their speech, we repeat their language and become able to control our output, as we fail to repeat accurately, we exert some control over the speaker.

The research question developed for this study was as follows:

Does shadow-reading as a means of internalization of meaning affect reading ability of Iranian EFL learners?

\section{Literature Review}

\subsection{Comprehension and Vygotskyan Paradigm}

Comprehension has been viewed from two distinctively different perspectives, while one perspective emphasizes meaning distraction, the other puts emphasis on meaning construction. According to

"The meaning-extracting process heavily relies on the idea that meaning is embedded in texts and readers/listeners extract this meaning from the text, making connections between new information obtained from the text and their prior knowledge, drawing inferences and evaluating the author's intent encoded in the text. Such a vision of the meaning making process, linked to the container metaphors of communication, has long dominated L2 comprehension research. It is based on the idea that "texts contain meaning [and] language is a neutral transparent medium for carrying meaning" (Kern, 2000, p. 49).

On the other hand, propo67nents of the meaning constructing argue that the meaning-extracting model does not adequately capture the complexities of human communication and can be compared to the transmission of information via a fax machine (Kern, 2000). Lantolf (1994) maintains that in human communication (e.g., in conversations), meaning is not determined ahead of time, but is created at the moment when utterances are produced. In this viewpoint, meaning is constructed by all the members involved in the communication at the confluence of language and context.

The triangle of comprehension, meaningfulness and cognition are closely interrelated concepts without each of which, learning goes astray. To combat learning difficulties, and to unravel learning and comprehension mechanism, scholars have proposed different approaches. Recently Second Language Acquisition (SLA) has adopted sociocultural theory of Vygotsky as the new perspective to justify how learning happens and progresses. In this approach, sociocultural factors have found their way into the development of L2 achievement. Sociocultural Theory (SCT) has its roots in the writings of the Russian psychologist Vygotsky. According to Ratner (2002), SCT suggests that human mental functioning is fundamentally a mediated process that is organized by cultural artifacts, activities, and concepts. Being in this way, humans are considered as collective entities to utilize existing cultural artifacts. They can create new artifacts that allow them to regulate their biological and behavioral activity. Language in this view is the main means of mediation and speaking practically and its development are primarily related to the cultural, social and linguistic, and historically formed settings such as family life and peer group interaction, and in institutional contexts like schooling, organized sports activities, and work place (Lantolf \& Thorne, 2006, p. 2). Although SCT considers human neurobiology as a condition for higher cognitive ability, the role of interaction within the social and material environments is determined as the most important factor in promoting cognition.

SCT is a construct firstly used by Vygotsky to overcome the crisis he once called "crisis in psychology". (Vygotsky, 1978, p. 26). The crisis emerged because of having many different psychological approaches and 
perspectives to study human mental abilities and specially her psychological attributes, though all of them appear with the label "psychology". The psychological approaches were grouped under two broad categories, one of them followed natural science approach (for instance behaviourism emphasizing on behaviours) and the other called humanistic psychology, which emphasized the description and understanding of mental activity (e.g., psychoanalysis). The second approach focused on what Vygotsky considers as higher mental processes problem-solving, voluntary memory and attention, rational thought, planning, and meaning making activity (Lantolf \& Thorne, 2006, p. 3). For Vygotsky (1978), human mind consists of two different bases: a lower-level neurobiological base, and a distinctive dimension of human consciousness which has the capacity for voluntary control over biology through the use of higher-level cultural tools (i.e., language, literacy, numeracy, categorization, rationality, logic). The higher level cultural tools acts as a buffer between the person and the environment mediating the relationship between individual and the social-material world.

Kern (2000) points out that the predominance of the cognitive dimensions in L2 research, particularly in comprehension research, makes an illusion that, for example, reading acquisition is "a naturally occurring process" and not "a socially constructed phenomenon" (p. 34). In Kern's view, the inclusion of a sociocultural dimension in the Vygotskyan tradition would allow L2 research to account better for social factors and might enhance our grasp of what happens when language learners try to produce or to understand spoken or written discourse. As Kern (2000) asserts, there must be a multidisciplinary approach which includes not only cognitive but also social and cultural dimensions to reveal a broader understanding of how comprehension takes place. Vygotsky repeatedly $(1987,1996,1997)$ has discussed the problem of comprehension as related to the critical role that it plays in the learning process. Vygotsky stipulates:

"Scholars think that understanding is greater with slower reading; however, actually with rapid reading, understanding is better [because] the different processes occur at different rates and the rate of understanding is more compatible with a rapid reading rate. Unfortunately, experimental research has thus far studied reading as a sensory-motor habit and not as a mental process of a very complex order. To a certain degree, the work of the visual mechanism is subordinate to the processes of understanding" (1997, p. 143).

Regarding mental processes which shape our understanding, he further asserts that:

"It is clear to us that understanding does not mean that in reading each sentence we generate pictures [images] of all objects mentioned in it [sentence]. Understanding cannot be reduced to a graphic resurrection of the object or even to naming of the word; more likely, it consists in operating with the sign itself and referring it to meaning, to a rapid movement of attention, and isolating different points that are at the center of our attention. Concentration of attention, attaching it to each separate sign, inability to control attention and transfer it so as to be oriented in the complex internal space that might be called a system of relations are the imbecile's basic traits of understanding the text".

As related to reading comprehension, Vygotsky (1996) claims that reading is a complicated process development of which is tightly related to the child's development of thinking. He further compares reading comprehension with problem solving in mathematics. With having enough knowledge of lexical items, one can select elements to the situation and put them "in order to determine their relevance for text comprehension... The process of reading and the teaching of reading are tightly linked to the development of inner speech." (pp. 209-211)

Two key theoretical constructs coming from Vygotskyian thinking are Scaffolding and Zone of Proximal Development ZPD). Scaffolding refers to Vygotsky's notion of the social-cultural interaction between a more skilled learner and a less skilled learner (Berk \& Winsler, 1995). For Vygotsky (1986), Zone of Proximal Development is the essential "ingredient" in effective instruction and defined as the discrepancy between a child's actual mental age and the level he reaches in solving problems with assistance. Vygotsky describes ZPD as the area of immature, but maturing (psychological) process. ZPD is recognized with two features; first, it is a measure of the child's potential ability (Vygotsky, 1986). Second, it is something which must be created by the interactions within the child's learning experience (Vygotsky, 1987). Then, the fundamental characteristic of ZPD from either feature is the necessity for collaboration or assistance from another more able partner. As Luckin and du Boulay (1999) assert, the need for this more able learning partner comes from the belief that the activities which constitute a part of the child's education must be beyond the range of her/his independent ability.

Within a Vygotskian paradigm, effective instruction involves the teacher (or more able peer) acting as a partner, enabling the child in her pursuit of success. This requires the provision of appropriately challenging activities and the right quantity and quality of assistance $(1978$, p. 2). In this way, the learner will be introduced into the culture of her society and empowered as an autonomous learner (Becker \& Varelas, 1995). ZPD can be closely crystalized using two other constructs of the Zone of Available Assistance (ZAA) and the Zone of Proximal 
Adjustment (ZPA). Regarding adjustment-providing process, Adey (1996) points out that the assistance provided by a more able learning partner must consider the nature of the activity which is offered to the child and the help which is made available to her/him as they attempt to complete this activity. Any adjustment to either the activity, or more precisely the learner's role in the activity, or the help they are offered has to be consistent with the system's beliefs about the child's ZPD. The activity must put not much burden on the child's mind, but it must be possible for her/him to achieve success with some help from the system. According to Adey (1996), the learning experience might well be hard work for teacher and learner.

The ZAA includes the variety of qualities and quantities of assistance provided for the child by the more able partner. As Luckin and du Boulay $(1999$, p. 3) state "A system or teacher with a large ZAA has the potential, in principle, to deal with a wide variety of learners: it has the basic capabilities that could be applied." However, Murphey (1996) asserts that the assistance offered to the child must be consistent with child's current ZPD and this is where ZPA comes to into play. The ZPA presents a selection from the ZAA appropriate for the given educational situation. It is evident that with the impoverished ZAA, the realm of ZPA will be confined. The appropriate selection of ZPA from ZAA is a matter of concern, versatile ZAA increases the possibility of inappropriate ZPA selection.

One of the underlying bases of Vygotsky's thoughts is that concepts cannot be studied alone, but they have to be studied as a part of a systematic phenomenon. Concepts are either every day or scientific one. According to Vygotsky (1986), the contact point between the everyday and the scientific is collaboration within the Zone of Proximal Development. As Evans (1993) points out, knowledge of the subject to be learned must be in a flexible form and culturally consistent with that of the child if it has to be joint with her already existing knowledge structure. The members of an ecological community can be classified into a taxonomic structure which ranges from concepts with which the child is familiar, such as snail and grass, to those with which she is less familiar, such as consumer and producer.

\subsection{Reading Comprehension Ability}

According to Pani (2004) and Zhang (2010) comprehension ability and the strategy used by the learners are highly correlated and both affect the learners' achievement in second language acquisition. Cheng and Gao (2002, p. 171) state that there are two distinct strategies to improve reading comprehension among learners: question-first and passage-first reading strategies. Many teachers just emphasize preteaching vocabularies before starting reading the passage. As Sharp (2003) puts it, teachers' attempts to preteach vocabulary with definitions without its connotations and context, are inoperative. Song (1998) and Zhang (2010) also provide evidence on the point that low proficient learners compared to high proficient ones, just confine themselves to the reading text and their over-reliance on the linguistic features of the text is clearly discernible, while high proficient ones just make use of strategic resources and means to overcome comprehension crisis.

Dressler and Kamil (2006) and Grabe (2009) point out that many factors including topic familiarity, ESL proficiency, cultural schemata, and readers' beliefs and goals, as well as quality and amount of reading practice influence learners reading comprehension. In our current state of teaching reading comprehension in Iran, there is mainly one prominent predetermined lesson plan for most of reading comprehension classrooms, including pre-teaching new vocabularies and then reading the passage and answering the reading comprehension questions. In some other cases, the process is the opposite i.e. the question-first strategy is adopted and then the learners are required to read the text and after finding new words' meaning, they are required to answer the questions. Although many strategies are used in comprehension classes, our learners have still many problems understanding the text and retaining the meaning.

According to Chau, Wu, Julia Chen, and Lughmani (2012, p. 313):

Promoting higher order cognitive skills and important reading comprehension skills remain a much neglected area in non-Western (Asian) contexts, which partly explains students' poor reading comprehension performance.

As they assert, learners' performance is affected by the short duration of time allowed for the test, item difficulty, ESL proficiency (intermediate to low in this study), and variations in teaching practices in schools and fatigue. According to Chau et al. (2012), reading test scores are not the mere source of guessing one's comprehension as comprehension is influenced by many person-related factors including motivation, prior knowledge, and variations in teaching practices in schools. They also point out that reading comprehension is constrained by linguistic discourse, and pragmatic-level problems. Additionally, Chau, et al. (2012, p. 314) indicate that "the classroom ecology needs to be reconfigured to facilitate readers' own understanding of a text and build up interest and confidence in reading." While extracting meaning from the text, learners have difficulty connecting sentence parts together and it has been suggested by Chau, et al. that for promoting this ability, learners can be 
directed to write what they read since "reading and writing are interlinked, having a reciprocal effect on each other" (p. 314). They further suggest that reading must be viewed as an interactive, iterative process, one that involves the writer seeking to anticipate and answer questions from the reader on the one hand, and the reader attempting to predict the questions the writer will try to answer on the other, to put it in Widdowson's (1998, p. 711) words, this is a conspiracy dimension of reading, meaning that comprehension does not depend so much on knowing what the language means but it depends much on deducing what the writer might mean by language.

Having all the problems faced by learners in reading comprehension on mind, this study was set out to find a new way of practicing reading comprehension; namely, shadow-reading. It is an interactive technique of reading, in which learners are paired up and they take the role of reader, who is supposed to read the text, and the shadower, who has to repeat what (s)he hears. In the following, shadow-reading will be investigated in the frame of Vygotskyan Sociocultural Theory.

\subsection{Imitation, Comprehension and Shadow-Reading}

Stern (1970, p. 57), believes that language learning is mainly a matter of imitation. Brown (2014) asserts that imitation is a very meaningful activity that is contextualized and purposeful. Imitation has been recognized as a key term in the process of learning; however, this study mainly brings shadowing into focus as a type of imitation to see whether shadowing plays any role in improving reading comprehension. Shadow-reading is a classroom activity in which learners assist each other in reading an L2 text through interactive reading, repeating and summarizing (de Guerrero \& Commander, 2013). According to Murphey (2001, p. 4), repetition is the heart of shadow-reading which promotes "language learning and goes beyond the mere echoing of input material". Murphey believes that shadowing is a step between being other-regulated and self-regulated. At first, it seems that we are under the control of others' language (other-regulated), but as we repeat their speech, we repeat their language and become able to control our output, as we fail to repeat accurately, we exert some control over the speaker. As Murphey states (2001, p. 4):

In Vygotskyan theory, imitation constitutes the chief mechanism of internalization and a major component of developmental activity in the Zone of Proximal Development. It is through interaction with an expert that the learner is capable of reproducing the expert's action by utilizing those functions that are in the process of maturing. Ultimately, imitation in joint activity with others is the basis for independent creative performance. Through imitative behavior, a learner not only appropriates model affordances but also transforms them and extends them to new contexts.

Having all of the above mentioned statements on mind, one can conclude that an obviously felt gap exists in the realm of higher cognitive studies towards reading comprehension crisis. To fill it in, this study has adopted Vygotskyan sociocultural approach towards comprehension to see if shadow-reading as a means of internalization of meaning could have any effect on reading comprehension of Iranian EFL learners.

\section{Methodology}

\subsection{Participants}

Participants of this study were 52 junior EFL learners from Islamic Azad University of Khorasgan and Falavarjan, Isfahan, Iran who were randomly assigned to experimental and control groups. Their age range was between 19 and 26 and all were born, raised, and were residing in Iran. They were all born to Persian parents. They were majoring in English as foreign language. Regarding their social class, the information gained from learners' background questionnaire showed that all of them belonged to middle-class families and some of them held non-professional part-time jobs. The information was gathered using a demographic questionnaire which took them about 20 minutes to fill.

\subsection{Instruments}

The first instrument for the study was a pretest of reading comprehension to ensure that learners are at the same level of reading comprehension. This test consisted of four short passages followed by five questions. An Oxford Placement Test (2004) was also run as a means of proficiency measurement. Ten reading passages were also selected for applying shadow reading. At the end of the semester, a post reading of the same structure as the pretest was administered.

\subsection{Procedure}

This study was run in the second semester of the academic year of 2014 in Islamic Azad University of Khorasgan and Falavarjan branches. Firstly, 52 EFL junior students age-ranged from 19 to 26 were assigned to two groups of the experimental and the control. The experimental group received shadowing strategy while 
control group class was run as usual. In the first session of the semester, an OPT test of proficiency was conducted to both groups to assure that all the participants were at similar level of English proficiency. They were all intermediate EFL learners according to the results of OPT test. In the second session, a reading comprehension test was administered to the learners which took them an hour to respond. It was reliable due to the Cronbach's alpha reliability of .85, the test validity was confirmed by the experts. From the third session on, shadow reading strategy was adopted as a reading comprehension strategy and the learners were taught how to do it, they had to find a partner for themselves, one took the reader's role, and the other got the shadower's role and they practiced it to learn how to read and shadow. The instructor firstly read the text and emphasized the unknown words pronunciation and definition. When the instructor ensured that they had no difficulty reading the text, the learners began their tasks. The learners were paired up on their own interest without any enforcement from the instructor. In each session, a 120 to 130 word-long passage was distributed and the readers were required to read the passage word by word and the shadower was required to repeat what they heard three times (out loud, low voice repetition, and silent (subvocally). Then, the reader read the text sentence by sentence and the shadower just told what they remembered from the sentence without looking at the text. In the third run of the study, the reader read the whole paragraph and the shadower tried to remember what s/he had heard without looking at the text. After this phase of the study, the learners were required to write down what they could remember from the text. They were required to summarise what they understood from the text. Then, their role was switched and the reader now became a shadower for the second paragraph. In the last, session of the semester, a post test of reading comprehension was administered. The post test was also considered reliable because of having the Cronbach's alpha reliability of .90. The results were fed into SPSS (version24) and an ANCOVA was run to see if shadow reading had any effect on the learners' comprehension. Preliminary assumptions including the unequal sample sizes, normality and homogeneity of variances were examined and the results showed no violations of the assumptions.

\section{Results}

Table 1 summarizes the descriptive data for reading comprehension by the control and the experimental group. As tabulated, the mean difference between the two groups is more than two (reading comprehension mean for control group was 10.19 and for the experimental group, it was 12.35). This suggests that shadowing could positively and unequivocally affect reading comprehension in the experimental group.

Table 1. Descriptive statistics

\begin{tabular}{llll}
\hline Dependent Variable: POSTTEST & & & \\
\hline group2 exp. group1 control & mean & std. Deviation & $\mathrm{N}$ \\
\hline 1 & 10.19 & 4.030 & 26 \\
2 & 12.35 & 3.898 & 26 \\
Total & 11.27 & 4.073 & 52 \\
\hline
\end{tabular}

Table 2 tabulates the results for the equality of means of the two groups before applying shadowing. As can be seen, regarding learners' reading comprehension, the two groups were of equal variances and the null hypothesis indicating that there was no difference between the two groups is supported.

Table 2. Levene's test of equality of error variances ${ }^{\mathrm{a}}$

\begin{tabular}{llll}
\hline Dependent Variable: POST-TEST & & \\
\hline F & df1 & df2 & Sig. \\
\hline .95 & 1 & 50 & .136 \\
\hline
\end{tabular}

Tests the null hypothesis that the error variance of the dependent variable is equal across groups.

a. Design: Intercept + group + OPT + PRETOEFL.

Table 3 tabulates the results of the ANCOVA test with OPT as its covariate variable. As the table indicates, after applying shadowing, there can be seen a significant difference between the two groups of experimental and 
control after applying shadow reading strategy. P value equals .001 suggesting that the null hypothesis (shadow reading has not any effect on the reading comprehension) was rejected. Further, partial Eta square of .21 implies that although shadowing could be an effective instrument to improve reading comprehension, there must be other factors influencing reading comprehension. Moreover, as this table shows, proficiency (Sig. $=.44)$ has had no effect on the interaction between the pre and post-tests of reading comprehension.

Table 3. Tests of between-subjects effects

\begin{tabular}{|c|c|c|c|c|c|c|c|c|}
\hline \multicolumn{9}{|c|}{ Dependent Variable: POSTTEST } \\
\hline Source & $\begin{array}{l}\text { Type III Sum } \\
\text { of Squares }\end{array}$ & df & Mean Square & $\mathrm{F}$ & Sig. & $\begin{array}{l}\text { Partial Eta } \\
\text { Squared }\end{array}$ & $\begin{array}{l}\text { Noncent. } \\
\text { Parameter }\end{array}$ & $\begin{array}{l}\text { Observed } \\
\text { Power }^{\mathrm{b}}\end{array}$ \\
\hline $\begin{array}{l}\text { Corrected } \\
\text { Model }\end{array}$ & $627.417^{\mathrm{a}}$ & 3 & 209.139 & 45.878 & .000 & .741 & 137.633 & 1.000 \\
\hline Intercept & 15.007 & 1 & 15.007 & 3.292 & .076 & .064 & 3.292 & .428 \\
\hline Group & 59.997 & 1 & 59.997 & 13.161 & .001 & .215 & 13.161 & .945 \\
\hline $\mathrm{OPT}$ & 2.722 & 1 & 2.722 & .597 & .443 & .012 & .597 & .118 \\
\hline PRETEST & 541.009 & 1 & 541.009 & 118.678 & .000 & .712 & 118.678 & 1.000 \\
\hline Error & 218.814 & 48 & 4.559 & & & & & \\
\hline Total & 7450.000 & 52 & & & & & & \\
\hline Corrected Total & 846.231 & 51 & & & & & & \\
\hline
\end{tabular}

a. R Squared $=.741$ (Adjusted R Squared $=.725$ ).

b. Computed using alpha $=.05$.

\section{Discussion}

The results of applying shadowing clearly revealed the effect of shadowing on reading comprehension of Iranian EFL learners. This strategy might lend support to the Vygotskyan sociocultural theory in that working within ZPD, the potential ability of the learners by successive meaningful repetition, could mediate the relationship between the actual and potential ability of the learners.

As Kern (2000) puts it, there must be social and cognitive factors interacting to promote comprehension among learners and the results of the current study have clearly showed that social interaction (shadow reading here) came to help learners' comprehension. As Adey (1996) reports, the help provided by a more knowledgeable partner must be adjusted to the learner' ZPD so that it could enhance learners' comprehension. The results of the present study showed that shadow reading could play this mediating role in promoting comprehension; however, it seems that a triangle of infra-knowledge, assistance from a group and meaningful repetition must come together and go hand in hand to mediate English comprehension among learners. The results of this study also are in line with Pani's (2004) and Zhang's (2010) findings in that comprehension ability and the strategy which is used to promote comprehension are highly correlated.

According to Murphey (2001, p. 4), repetition is the heart of shadow-reading which promotes "language learning and goes beyond the mere echoing of input material". The results of this study support this idea in that meaningful imitation with the help of a more proficient learner could significantly affect learners' comprehension. The results of this study also give a boost to Murphey's statement that shadowing is a step between being other-regulated and self-regulated, at first it seems that we are under the control of others' language (other-regulated), but as we repeat their speech, we repeat their language and become able to control our output, as we fail to repeat accurately, we exert some control over the speaker. Reviewing the results of this study, it seems possible to state that shadow reading effectively influenced learners so that they could take control of their own understanding.

The results of the current study showed that all learners (both high and low proficient learners) could benefit from relying on linguistic features as well as sociocultural aspects via implementing shadowing. Shadowing could help learners view reading through a more flexible and interesting window; so that the tough, confusing and time-consuming process of reading comprehension becomes enjoyable with the help received by the low 
proficient partner. As Vygotsky (1978) asserts, comprehension is not achieved by mere gathering of the words meaning but it is something more than that; being in this way, the results of study lend support to his idea that comprehension is closely related to higher mental functions including psychological, social and cultural ones. As mentioned by Vygotsky (1996, p. 202), text comprehension is similar to problem solving in mathematics, one must know the rule to solve the problem although one does not notice the detailed process of coming to the last answer. Therefore, even if we do not know what happens in the mind while shadowing occurs, the result is that shadowing can mediate the mechanism of comprehension. As Vygotsky clarifies, an opportunity must be provided for the learners to interact with a more able partner and shadowing just provides such a golden opportunity.

The results also support Chau and colleagues' (2012) findings in that type of practicing reading comprehension in addition to proficiency and motivation influences learners' achievement in reading comprehension. The findings of this study further lends support to Chau, et al.'s (2012, p. 202) indicating that "the classroom ecology needs to be reconfigured to facilitate readers' own understanding of a text and build up interest and confidence in reading." All of these just lead us to claim that shadowing could effectively act on the ZPD and mediate the link between mechanical (reading through eyes), social (peer interactions), and psychological (comprehension) factors.

As was seen, the results of this study indicated that shadow-reading could work as a helpful means of facilitating the relationship between the ZPD and reading comprehension, which resulted in better comprehension. It seems that shadowing could be of much interest to learners, since it makes an interactive, cooperative and pleasing environment which mitigates the arduous and sometimes burdensome conditions of reading comprehension classes. This study also faced some limitations: it needs much time and energy on the part of the instructors to select appropriate reading texts and apply shadowing. Furthermore, this study was administered to junior students at two universities while it can be conducted for a wide range of EFL learners with different levels of English proficiency. It is suggested that shadow-reading be applied as a new and effective strategy and see if it has a significant effect on EFL learners' reading comprehension in different cultural and social contexts. Since in some cultures like Iranians', cooperation and interaction to promote learning are not pursued in its real sense, shadow-reading can be used as a motivating means for providing a suitable context to maintain the sense of cooperation among learners, to listen and repeat without anxiety and fear and to help each other with pleasure.

\section{References}

Adey, P. (1996). Cognitive acceleration and the zone of proximal development. (conference presentation). Paper presented at the abstracts of the second Conference for Sociocultural research, Geneva.

Becker, J., \& Varelas, M. (1995). Assisting construction: The role of the teacher in assisting the learner's construction of pre-existing cultural knowledge. In L. P. \& Steffe J. (Eds.), Constructivism in Education (pp. 433-446). Hillsdale. NJ: Lawrence Erlbaum Associates.

Berk, L., \& Winsler, A. (1995). Scaffolding children's learning: Vygotsky and early childhood education. Washington. D.C.: National Association for the Education of Young Children.

Bernhardt, E. B. (1991). Reading Development in a Second Language: Theoretical, Empirical, and Classroom Perspectives. Norwood, New Jersey: Ablex Publishing Corporation.

Brown, H. D. (2014). Principles of language learning \& teaching (6th ed.). White Plains, NY: Pearson. Centeno-Cortés.

Buck, G. (2003). Assessing Listening. Cambridge: Cambridge University Press.

Chau, J., Wu, W., Chen, J., \& Lughmani, Sh. (2012). Oxford ELT Journal, 66(3), 304-317. http://dx.doi.org/10.1093/elt/ccr088

Cheng, L. \& Gao, L. (2002). Passage dependence in standardized reading comprehension: exploring the college English test'. Asian Journal of English Language Teaching, 12, 163-78.

de Guerrero, M., \& Commander, M. (2013). Shadow-reading: Affordances for imitation in the language classroom. Language Teaching Research.

Dressler, C., \& Kamil, M. (2006). First- and second language literacy. In D. August, \& T. Shanahan (Eds.), Developing Literacy in Second-languag Learners. Mahwah, NJ: Lawrence Erlbaum Associates.

Evans, P. (1993). Some implications of work for special education. In H. Daniels (Ed.), Chartering the Agenda: Educational activity after Vygotsky (pp. 30-45). London: Routledge. 
Grabe, W. (2009). Teaching and testing reading. In M. H. Long, \& C. J. Doughty (Eds.), The Handbook of Language Teaching. Malden. MA: Wiley-Blackwell. http://dx.doi.org/10.1002/9781444315783.ch24

Kern, R. (2000). Literacy and Language Teaching. Oxford: Oxford University Press.

Luckin, R., \& du Boulay, B. (1999). Ecolab: The development and evaluation of a Vygotskian design framework. International Journal of Artificial Intelligence in Education, 10, 198-220.

Lantolf, J. P. (1994). Sociocultural theory and second language learning: Introduction to the special issue. The Modern Language Journal, 78, 418-420. http://dx.doi.org/10.1111/j.1540-4781.1994.tb02058.x

Lantolf, J. P., \& Thorne, S. L. (2006). Sociocultural theory and the genesis of second language development. Oxford University Press.

Murphey, T. (1996). Proactive adjusting to the zone of proximal development: Learner and teacher strategies. Paper presented at the 2nd Conference for Socio-cultural Research Vygotsky-Piaget, Geneva, 1-4.

Murphey, T. (2001a). Exploring conversational shadowing. Language Teaching Research, 5, 128-155. http://dx.doi.org/10.1177/136216880100500203

Murphey, T. (2001b). Tools of recursion, intermental zones of proximal development, \& critical collaborative autonomy. JALT Journal, 23, 130-150.

Pani, S. (2004). Reading strategy instruction through mental modeling. ELT Journal, 58(4), 355-62. http://dx.doi.org/10.1093/elt/58.4.355

Roebuck, R. (1998). Reading and Recall in L1 and L2: a Sociocultural Approach. Stamford: Ablex Publishing Corporation.

Sharp, A. (2003). Reading Comprehension and Text Organization. New York: Edwin Mellen Press.

Song, M. (1998). Teaching reading strategies in an ongoing EFL university reading classroom. Asian Journal of English Language Teaching, 8, 41-54.

Stern, H. H. (1970). Fundamental Concepts of Language Teaching. Oxford University Press.

Swaffar, J. K., Arens, K. M., \& Byrnes, H. (1991). Reading for Meaning: an Integrated Approach to Language Learning. Englewood Cliffs: Prentice Hall.

Vygotsky, L. S. (1978). Mind in society: The development of higher psychological processes. In M. Cole, V. John-Steiner, S. Scribner, \& E. Souberman, (Eds. and Trans.). Cambridge, MA: Harvard University Press. (Original work published 1934).

Vygotsky, L. S. (1986). Thought and language. Cambridge, MA: The MIT Press.

Vygotsky, L. S. (1996). Anthology of humanistic pedagogy. Moskva: Smysl

Vygotsky, L. S. (1997). Educational psychology. Boca Raton, FL: St. Lucie Press.

Widdowson, H. G. (1998). Context, community, and authentic language. TESOL Quarterly, 32(4), 705-16. http://dx.doi.org/10.2307/3588001

Zhang, L. J. (2010). A dynamic metacognitive systems account of Chinese university students' knowledge about EFL reading. TESOL Quarterly, 44(2), 320-53. http://dx.doi.org/10.5054/tq.2010.223352

\section{Copyrights}

Copyright for this article is retained by the author(s), with first publication rights granted to the journal.

This is an open-access article distributed under the terms and conditions of the Creative Commons Attribution license (http://creativecommons.org/licenses/by/3.0/). 